\title{
Nephroblastoma presenting with acute hepatic encephalopathy
}

\author{
S Kinmond, R Carter, C H Skeoch, N S Morton
}

\begin{abstract}
A 3 year old girl presented with Budd-Chiari syndrome of acute onset, and hepatic encephalopathy secondary to intravascular extension of a Wilms' tumour shown on echocardiography. After a period of intensive medical treatment the tumour was removed, cardiopulmonary bypass with hypothermic circulatory arrest being necessary. Her hepatic failure resolved and she made a complete neurological recovery.
\end{abstract}

Wilms' tumour may be diagnosed after an abdominal mass or hypertension is detected on routine examination, or may present with abdominal distension, pain, or occasionally haematuria. We describe the diagnosis and management of a child who presented with a very unusual complication.

\section{Case report}

A 3 year old girl with well controlled phenylketonuria presented with a 24 hour history of lethargy, abdominal pain, and vomiting. She was moderately dehydrated with poor peripheral perfusion. The liver was enlarged and the right kidney was palpable. She was not jaundiced and had no signs of chronic liver disease. Neurological assessment was satisfactory (Glasgow coma scale 14). She was rehydrated and treated with antibiotics for presumed sepsis.

During the next 12 hours she showed signs of neurological deterioration (Glasgow coma scale 7), with extensor plantar reflexes; there was progressive liver enlargement $(4 \mathrm{~cm}$ below the costal margin) associated with the development of ascites and, later, bilateral pleural effusions. An electroencephalogram showed diffuse slow wave activity. Biochemical and haematological investigations supported the diagnosis of hepatic failure (table). Clinically the patient was in grade 4 hepatic coma.
Abdominal ultrasound scan showed dilatation of the hepatic veins and a mass in the right upper quadrant $(8 \times 7 \times 6 \mathrm{~cm})$, and an intravenous urogram showed distortion and displacement of the right pelvicaliceal system. Echocardiography showed a mass extending from the inferior vena cava into the right atrium.

The patient was intubated after being given oxygen, fentanyl, thiopentone, and suxamethonium, and was ventilated using pancuronium $(0.15 \mathrm{mg} / \mathrm{kg})$ for muscle relaxation and an infusion of morphine $(0.06 \mathrm{mg} / \mathrm{kg} / \mathrm{hour})$ for sedation. She was treated with enteral lactulose and neomycin; hyperosmolar dextrose was infused through a central venous catheter. Coagulation was corrected with vitamin $\mathrm{K}$ and blood products. A thermodilution pulmonary artery catheter with triple lumen flow was then inserted to allow measurement of cardiac output and cardiac filling pressures, and a catheter for monitoring intracranial pressure was sited using a frontal approach to the right lateral ventricle. ${ }^{1}$

Cerebral perfusion pressure was maintained by titrating colloid and inotropic agents (dopamine $10 \mu \mathrm{g} / \mathrm{kg} / \mathrm{min}$ and dobutamine $15 \mu \mathrm{g} / \mathrm{kg} /$ min) to support systemic mean arterial pressure, and by controlling intracranial pressure with moderate hyperventilation (carbon dioxide pressure $3.5-4.0 \mathrm{kPa}$ ). Increases in intracranial pressure were treated with mannitol $(0.25 \mathrm{~g} / \mathrm{kg})$, thiopentone $(4 \mathrm{mg} / \mathrm{kg})$, or removal of cerebrospinal fluid. A total of $35 \mathrm{ml}$ were drained over 18 hours. Frusemide $(0.5 \mathrm{mg} / \mathrm{kg} /$ hour $)$ was given by intravenous infusion, and prostacyclin (20 $\mathrm{ng} / \mathrm{kg} / \mathrm{min}$ ) was given as a vasodilator.

Despite this intensive management the cerebral perfusion pressure briefly fell below $4 \cdot 7$ $\mathrm{kPa}(35 \mathrm{mmHg}$ ) on several occasions over a 24 hour period. Surgical relief of the obstruction to the inferior vena cava was considered to be the only treatment that could reverse the patient's fulminant hepatic failure. A routine cardiac surgical anaesthetic was given, and a midline laparotomy done to allow intraoperative assessment
Intensive Therapy Unit, Royal Hospital for Sick Children,

Glasgow

$S$ Kinmond

R Carter

C H Skeoch

N S Morton

Correspondence to:

Dr $S$ Kinmond,

Department of

Medical Paediatrics,

Royal Hospital for

Sick Children,

Yorkhill,

Glasgow G3 8SJ.

Accepted 13 December 1989

(ArchDisChild 1990;65:542-3)
Results of laboratory investigations

\begin{tabular}{|c|c|c|c|c|c|c|c|}
\hline & \multicolumn{4}{|l|}{ Before operation } & \multicolumn{3}{|c|}{ After operation } \\
\hline & On admission & 12 hours & 24 hours & 36 hours & Day 1 & Day 7 & Day 28 \\
\hline \multirow{6}{*}{$\begin{array}{l}\text { Serum glucose concentration } \\
\quad(\mathrm{mmol} / \mathrm{l}) \\
\text { Plasma ammonia concentration } \\
\quad(\mu \mathrm{mol} / \mathrm{l}) \\
\text { Aspartate aminotransferase } \\
\text { activity (U/I) } \\
\text { Alanine aminotransferase } \\
\text { activity (U/I) } \\
\text { Serum bilirubin concentration } \\
\quad(\mu \mathrm{mol} / \mathrm{l}) \\
\text { Prothrombin time (seconds) } \\
\left.\text { Platelet concentration ( } \times 10^{9} / \mathrm{l}\right) \\
\text { Plasma phenylalanine concentration } \\
\quad(\mu \mathrm{mol} / \mathrm{l})\end{array}$} & $6 \cdot 7$ & $17 \cdot 2$ & $8 \cdot 5$ & $8 \cdot 3$ & $6 \cdot 4$ & \multicolumn{2}{|c|}{ Not measured } \\
\hline & 124 & Not measured & 167 & Not measured & & & \\
\hline & Not measured & 548 & 1336 & Not measured & 3249 & 129 & 33 \\
\hline & Not measured & 243 & 566 & 2468 & 894 & 449 & 32 \\
\hline & $\begin{array}{l}\text { Not measured } \\
\text { Not measured } \\
326\end{array}$ & $\begin{array}{r}7 \\
41 \\
143\end{array}$ & $\begin{array}{l}15 \\
25 \\
69\end{array}$ & $\begin{array}{l}26 \\
25 \\
56\end{array}$ & $\begin{array}{l}60 \\
26 \\
98\end{array}$ & $\begin{array}{r}33 \\
18 \\
198\end{array}$ & $\begin{array}{l}17 \\
\text { Not measured } \\
389\end{array}$ \\
\hline & 425 & 919 & Not mea & sured & 1820 & 1375 & 910 \\
\hline
\end{tabular}


of the tumour, and confirm that there were no intraabdominal metastases. Subdiaphragmatic venous congestion prevented more than minimal preliminary dissection.

The incision was extended into a median sternotomy and the intravascular tumour was found to extend into the lower right atrium. Cardiopulmonary bypass was established through the right atrial appendage and the aortic root. The patient was cooled to $20^{\circ} \mathrm{C}$ and the circulation slowed. This allowed mobilisation of the tumour mass and subsequent division of the renal pedicle at the hilum, giving access to the inferior vena cava below a grossly enlarged and engorged liver.

Circulatory arrest was then induced, the superior vena cava was snared, and the inferior cavoatrial junction opened. The combined subhepatic and suprahepatic approach allowed complete removal of the tumour thrombus from the inferior vena cava and hepatic veins. This was accompanied by visible decongestion of the liver. The venotomy and atriotomy were closed and the patient rewarmed to $37^{\circ} \mathrm{C}$ before discontinuing bypass without difficulty. The chest and abdomen were closed with routine drainage.

Her postoperative recovery was uneventful. She was extubated on the fifth day after operation, at which time she was fully conscious (Glasgow coma scale 14). Histology showed a nephroblastoma with a 'favourable' histological appearance, and confirmed tumour fragments within the intravascular thrombus. Chemotherapy was delayed for two weeks until liver function tests had improved, and the patient is now receiving a chemotherapy regimen modified from the United Kingdom Children's Cancer Study Group protocol for stage II nephroblastoma with favourable histology, and is tolerating this treatment well. Satisfactory control of her phenylketonuria was eventually regained 11 weeks after operation.

\section{Discussion}

Intravascular extension of hepatocellular, adre- nal, or renal carcinoma is a well recognised cause of the Budd-Chiari syndrome ${ }^{2}$ but rarely presents with encephalopathy. Intra-atrial extension may occur in up to $0.7 \%$ of cases of Wilms' tumour ${ }^{3}$; we have, however, found only one previous report of Budd-Chiari syndrome in this condition. ${ }^{4}$ We believe this to be the first reported case of fulminant hepatic failure caused by hepatic venous obstruction in a patient with a Wilms' tumour.

Intraventricular monitoring of intracranial pressure has been questioned in the management of hepatic encephalopathy in view of the risk of intracranial haemorrhage. ${ }^{5}$ In this case vigorous treatment was required to maintain cerebral perfusion pressure before operation, and the therapeutic option of withdrawal of cerebrospinal fluid was invaluable in stabilising the patient. There were no complications.

Fulminant hepatic failure in children has a mortality of almost $70 \%$, but the hepatic and neurological prognosis for survivors is good. ${ }^{6}$ This case illustrates a rare but reversible cause of fulminant hepatic failure and the use of circulatory arrest in facilitating removal of an otherwise inoperable tumour. The successful outcome resulted from a multidisciplinary approach to management and, despite the patient's critical condition, early operative decompression after stabilisation was both feasible and lifesaving.

We thank Professor F Cockburn, Mr AHB Fyfe, Mr M Jamieson, and Dr EM Simpson for permission to report their patient.

1 McWilliam RC, Stephenson JBP. Rapid bedside technique for intracranial pressure monitoring. Lancet 1984;ii:73-

2 Mitchell MC, Boitnott JK, Kaufman S, Cameron JL, Maddrey WC. Budd-Chiari syndrome: etiology, diagnosis and management. Medicine 1982;61:199-218.

3 Nakayama DK, DeLorimier AA, O'Neil JA, Norkool P, D'Angio GJ. Intracardiac extension of Wilms' tumour A report of the National Wilms' Tumour Study. Ann Surg 1986;204:693-7.

4 Schraut WH, Chilcote RR. Metastatic Wilms' tumour causing acute hepatic vein occlusion (Budd-Chiari syndrome). ing acute hepatic vein occlusion

5 Ede R, Keays R, Williams R. Intracranial pressure monitoring and management of encephalopathy. (iare of the Critically Ill 1989;5:46-8.

6 Mowat AP. Fulminant hepatic failure. Liver disorders in childhood. 2nd ed. London: Butterworths, 1987:126.
Institute of

Pathologic Anatomy,

University of Siena, Italy

M M De Santi

Cystic Fibrosis Centre,

Verona, Italy

E A Valletta

Institute of

Pathology,

University of

Siena, Italy

C Gardi

G Lungarella

Correspondence to: Dr A Magni,

Cystic Fibrosis Centre,

Ospedale Civile Maggiore,

Piazzale Stefani 1,

37126 Verona, Italy.

Accepted 7 December 1989 (ArchDisChild 1990;65:543-4)

\title{
Hydrocephalus, bronchiectasis, and ciliary aplasia
}

\author{
M M De Santi, A Magni, E A Valletta, C Gardi, G Lungarella
}

Abstract

A girl presented in the neonatal period with hydrocephalus, bronchiectasis, and ciliary aplasia. A common defect both in respiratory tract cilia and in ventricular ependyma cilia may explain the association of the two diseases.

Hydrocephalus has recently been described in a child in association with primary ciliary dyskinesia. ${ }^{1}$ Although hydrocephalus is not a constant feature of the disease, the association may be of interest in suggesting a functional role for the cilia lining the ventricular ependyma of the brain and spinal cord. In this paper we report a particular form of primary ciliary dyskinesia (ciliary aplasia) in a girl with bronchiectasis who developed hydrocephalus in the neonatal period.

\section{Case report}

A girl, the first child of unrelated parents, was spontaneously delivered at full term after a normal pregnancy. At the age of 3 weeks an increased cranial circumference was noted. Computed tomography showed triventricular hydrocephalus caused by stenosis of the aqueduct of Sylvius. A ventriculoatrial shunt 